\title{
Pembuatan Instrumen Akuisisi Data Seismik Refraksi Murah dan Layak Pakai Dalam Upaya Membangun Kemandirian Instrumentasi Geofisika
}

\author{
Wahyudi $^{*}$ and Anas Setyo Handaru
}

\begin{abstract}
Ringkasan
Survei dalam metode geofisika selalu menggunakan instrumen dalam pengambilan datanya. Terbatasnya instrumen geofisika buatan dalam negeri membuat ketergantungan instrumen buatan luar negeri sangat besar. Oleh karena itu, perlu dibangun kemandirian untuk memproduksi instrumen geofisika, sehingga nantinya tidak ada lagi ketergantungan terhadap instrumen produksi luar negeri. Pembangunan kemandirian ini dimulai dengan membuat salah satu instrumen geofisika untuk akusisi Seismik Refraksi. Pada penelitian ini telah dirancang dan dibangun sebuah instrumen untuk akuisisi seismik refraksi yang murah dan reliabel. Sistem, cara kerja, dan komponen-komponen yang dipakai akan mengadopsi dan memodifikasi teknologi terbaru dari alat akuisisi seismik refraksi saat ini. Alat yang diimplementasikan nantinya diharapkan dapat dipakai untuk proses perkuliahan maupun survei seismik refraksi di lapangan. Oleh karena itu, pada penelitian ini juga telah dilakukan pengujian terhadap alat tersebut.
\end{abstract}

Kata Kunci : seismik refraksi, instrumentasi

\begin{abstract}
Surveys in geophysical methods always use the instrument in the data retrieval. The limited local-made geophysical instruments make the enormous dependence of foreign-made instruments. Therefore, it is necessary to build independence to produce geophysical instruments, so that later there will be no more dependence on foreign-made instruments. The development of this independence begins with making one of the geophysical instruments for the acquisition of Refraction Seismic Instrument. An instrument for the acquisition of cheap and reliable refraction seismic will be designed and built. The systems, workings, and used components adopt and modify the latest technology of the current seismic acquisition instrument. Implemented tools are expected to be used for lectures and seismic surveys in the field.
\end{abstract}

Keywords: Seismic Refraction; Instrumentation

\section{Pendahuluan}

Dalam seismik aktif, ketika gelombang seismik melewati batas antara dua jenis batuan, sebagian akan terpantulkan dan sisanya akan diteruskan dengan pembelokan arah perambatan. Fenomena ini mengikuti hukum snellius [1]. Pada umumnya semakin dalam batuan dari permukaan, maka kecepatan gelombang seismik pun akan semakin cepat. Oleh karena itu ketika gelombang seismik melewati batas lapisan batuan, gelombang yang terbiaskan akan

\footnotetext{
${ }^{*}$ Correspondence: wahyudi_mipa@ugm.ac.id

Department of Physics, Universitas Gadjah Mada, Sekip Utara PO BOX

BLS 21, 55281 Yogyakarta, Indonesia

Full list of author information is available at the end of the article

${ }^{\dagger}$ Equal contributor
}

menjauhi garis normal yang artinya mendekati batas perlapisan. Ketika sudut datang gelombang tersebut melewati sudut kritis maka pembiasan gelombang tersebut akan menjalar di sepanjang batas perlapisan batuan dan kembali ke permukaan sebagai head wave. Fenomena terbentuknya head wave inilah yang menjadi dasar dalam metode refraksi [2].

Adapun penelitian ini dilatarbelakangi oleh terbatasnya instrumen akuisisi geofisika produksi dalam negeri membuat ketergantungan akan instrumen produksi sangat tinggi. Umumnya instrument pabrikan luar negeri memiliki biaya yang sangat besar sehingga jumlah instrumen yang dimiliki untuk proses perkuliahan juga terbatas. Hal 
ini jugalah yang menghambat proses pembelajaran dalam kuliah akibat keterbatasan instrumen. Salah satu solusi dari permasalahan ini dapat diselesaikan jika instrumentasi dapat dikerjakan sendiri oleh kalangan akademisi internal bahkan oleh mahasiswa itu sendiri. Oleh karena itu, perlu adanya upaya untuk membangun kemandirian dalam instrumentsai geofisika.

Langkah tersebut dimulai dengan membuat instrumen akuisisi data seismik refraksi. Pada penelitian ini telah dirancang dan dibangun instrumen akuisisi data seismik refraksi yang layak pakai dengan biaya yang murah. Instrumen yang akan dibangun akan mengusung teknologi terkini yang telah ada di pasaran. Penelitian ini juga diharapkan dapat menjadi pilot project dalam membangun alat-alat geofisika yang lain, sehingga kemandirian dalam instrumentasi geofisika dapat terbangun.

\section{Desain}

Instrumen yang akan dibuat merupakan rintisan instrumen akuisisi seismik refraksi yang selanjutnya akan terus dikembangkan dengan teknologi-teknologi terbaru sesuai perkembangan zaman. Gambar 1 adalah rancangan blok diagram dari instrumen yang akan diimplementasikan. Desain ini mengacu pada teknologi terbaru dari instrumen di pasaran.

Instrumen yang didesain terdiri dari tiga bagian, yaitu unit digitasi (Digitizer Unit, unit pengumpul (Collector Unit), dan perangkat lunak untuk menampilkan rekaman. Unit digitasi bertugas untuk mengkonversi sinyal analog dari geophone ke sinyal digital. Unit ini dilengkapi dengan penguat sinyal (amplifier) dan memory yang bertugas untuk menyimpan data yang bersifat sementara. Data pada memory tersebut selanjutnya akan dikumpulkan secara kolektif ke unit pengumpul secara bergantian. Unit Pengumpul juga bertugas untuk memberi isyarat kepada unit digitasi kapan waktu perekaman dimulai. Unit ini akan memberi isyarat kepada seluruh unit digitasi untuk merekam data secara simultan. Pada penelitian ini juga akan dirancang perangkat lunak untuk menampilkan rekaman hasil pengukuran.

Pada desain ini digitizer tidak tersentralisasi pada unit utama (main unit), tetapi berdiri sendiri secara modular dan berpasangan dengan masing-masing geophone. Pada desain ini, tidak terdapat proses multiplexing seperti pada teknologi sebelumnya, sehingga tidak terdapat kesalahan time shifting pada data rekaman. Teknik ini juga memungkinkan minimnya gangguan induksi yang biasanya terjadi pada sistem digitalisasi sentral.

Penelitian ini dimulai dengan merakit unit digitasi. Unit digitasi terdiri dari penguat sinyal/amplifier, analog to digital converter, memory dan mikrokontroler. Setelah perakitan dilakukan, selanjutnya adalah melakukan uji coba dan kalibrasi. Ada beberapa hal yang perlu diperhatikan pada tahap ini. Pertama, amplifikasi sinyal analog dari geophone harus akurat dan terhindar dari derau. Kedua, kecepatan cuplik dan hasil cupliknya dari ADC juga harus stabil dan akurat. Untuk itu kalibrasi difokuskan pada kedua komponen ini. Selanjutnya perlu dilakukan uji durabilitas dan konsumsi daya dari mikrokontroler. Bila seluruh pengujian baik dan berfungsi stabil maka lanjut pada tahap berikutnya.

Tahap berikutnya adalah perakitan, uji coba, dan kalibrasi unit pengumpul. Unit ini terdiri dari mikrokontroler, memory, baterai, dan regulator daya. Pada tahap ini hal yang perlu di fokuskan adalah tentang komunikasi mikrokontroler pada unit ini dengan unit digitasi. Bagian ini sangat penting mengingat timing merupakan hal yang sangat penting pada pengukuran rambat gelombang seismik. Unit pengumpul harus mampu memberi isyarat kepada seluruh unit digitasi agar mampu merekam secara simultan. Hal yang tak kalah penting adalah kemampuan unit pengumpul untuk mengumpulkan data dari masing-masing unit digitasi agar sesuai dengan urutan yang benar. Pada unit ini terdapat catu daya untuk seluruh sistem instrumen. Pada tahap ini juga akan di uji daya tahan baterai, sehingga didapatkan durasi penggunaan alat maksimal. Jika seluruh pengujian baik dan berfungsi stabil maka dilanjutkan pada tahap berikutnya.

Tahap selanjutnya adalah pembuatan perangkat lunak yang berfungsi untuk menampilkan rekaman dan integrasi seluruh unit. Setelah tahap ini selesai maka tahap selanjutnya dilakukan pengujian lapangan dan membanding-kannya dengan alat survei refraksi buatan pabrik. Jika pengujian lapangan baik dan berfungsi normal maka penelitian selesai.

\section{Hasil}

\subsection{Unit Digitasi}

Unit digitasi tersusun atas satu unit mikrokontroler, satu Analog to Digital Converter (ADC), penyimpan data (flash memory) dan satu i2c expander. Semua komponen ini terhubung dengan mikrokontroler sebagai pusat dari seluruh rangkaian unit digitasi. Gambar 2 merupakan kenampakan dari unit digitasi yang telah di rakit.

Mikrokontroler berfungsi untuk mengatur seluruh aktivitas dari komponen. Pada komponen ini dilakukan pemrograman agar unit ini mampu mengatur seluruh komponen yang terhubung dengannya. Pada unit digitasi ini, Arduino Promico digunakan sebagai mikrokontroler. Perangkat ini 


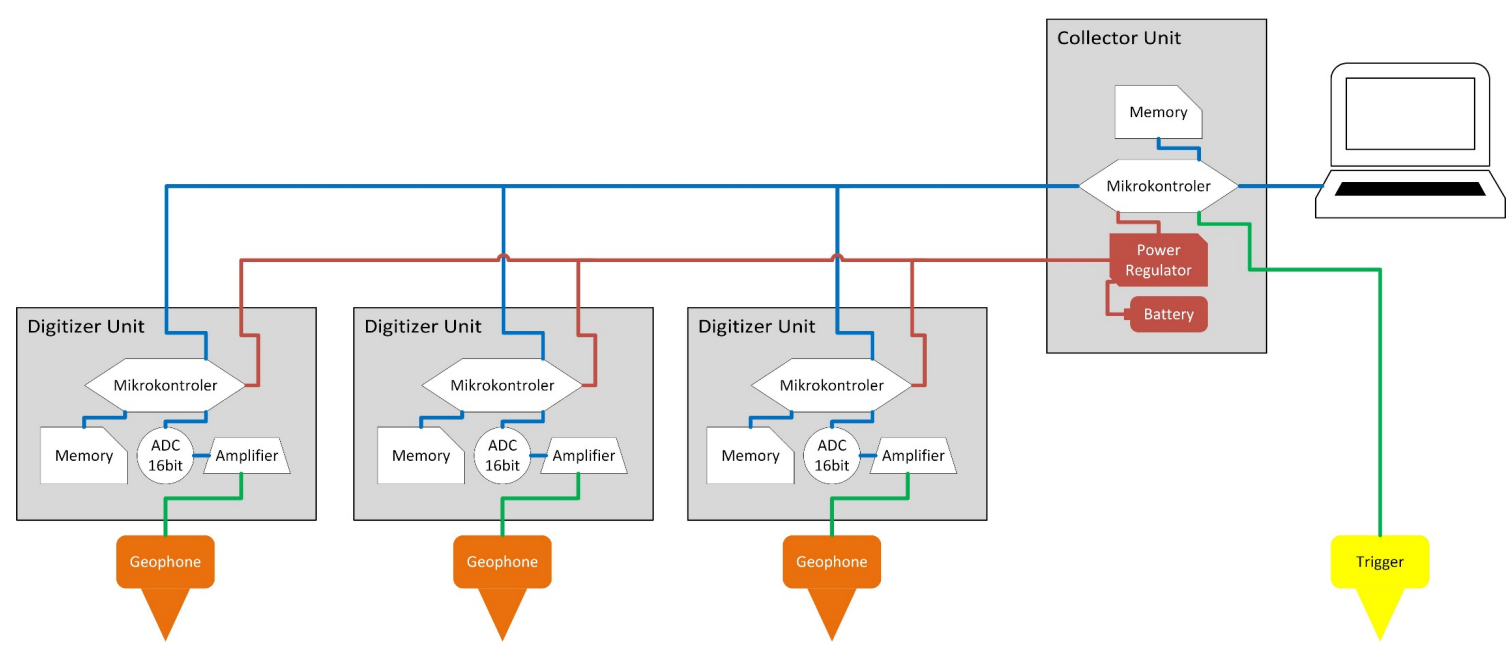

Gambar 1 Desain instrumen akuisisi data seismik refraksi, terdiri dari dua bagian utama yaitu Unit Digitasi dan Unit Kolektor

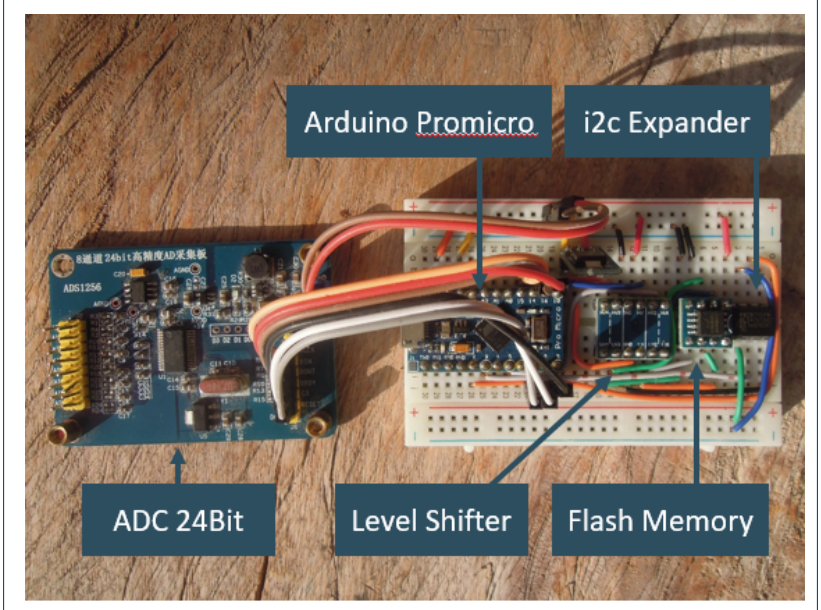

Gambar 2 Unit digitasi dan komponen penyusunnya.

dipilih karena memiliki ukuran yang relatif kecil dan memiliki konsumsi daya yang rendah. Perangkat ini bekerja dengan logic level sebesar $5 \mathrm{~V}$ dengan frekuensi 16 MHZ.

Analog to Digital Converter (ADC) berfungsi untuk mengubah keluaran dari geophone yang berupa sinyal analog menjadi sinyal digital. Sinyal digital dari keluaran ADC ini kemudian diteruskan ke perangkat penyimpanan melalui mikrokontroler. Kemampuan digitasi dari unit digitasi ini ditentukan oleh ADC. Pada perakitan instrumen ini digunakan modul ADC ADS1256 yang memiliki resolusi 24bit dan kecepatan cuplik maksimal 30.000 sampel per detik. Komponen ini terhubung dengan mikrokontroler dengan komunikasi SPI (Serial Periperal Interface).
Komponen penyimpan data (flash memory) berfungsi sebagai tempat penyimpan data sementara pada setiap unit digitasi. Nantinya data yang telah tersimpan dalam unit penyimpanan dikirim ke unit pengumpul. Komponen penyimpanan yang digunakan adalah winbond W25Q32FV. Komponen penyimpanan ini memiliki kapasitas sebesar 32M-bit. Perangkat ini mampu menyimpan data dari ADC hingga 1 juta sampel. Komponen ini terhubung dengan mikrokontroler dengan komunikasi SPI (Serial Periperal Interface).

Unit pengumpul dan unit digitasi saling terhubung dengan komunikasi berjenis $12 \mathrm{C}$ namun perangkat keras dari komunikasi ini hanya mampu menyalurkan data tidak lebih panjang dari dua meter. Oleh karena itu diperlukan penguat sinyal berupa i2c extender pada unit digitasi ini agar komunikasi dapat terjalin dengan kabel hingga 50 meter.

\section{B. Unit Pengumpul}

Unit pengumpul tersusun atas mikrokontroler, i2c extender dan analog to digital converter (ADC). Semua komponen ini terhubung dengan mikrokontroler sebagai pusat dari seluruh rangkaian unit digitasi. Gambar 3 merupakan kenampakan dari unit pengumpul yang telah dirakit.

Mikrokontroler yang digunakan adalah Arduino Mega 2560. Arduino Mega adalah papan mikrokontroler berbasis ATmega1280. Mikrokontroler ini memiliki 54 pin input / output digital (dimana 14 dapat digunakan sebagai output PWM), 16 input analog, 4 UART (port serial perangkat keras), osilator kristal $16 \mathrm{MHz}$, koneksi USB, colokan listrik, header ICSP, dan tombol reset. Ini berisi semua yang dibutuhkan untuk mendukung mikrokontroler. 


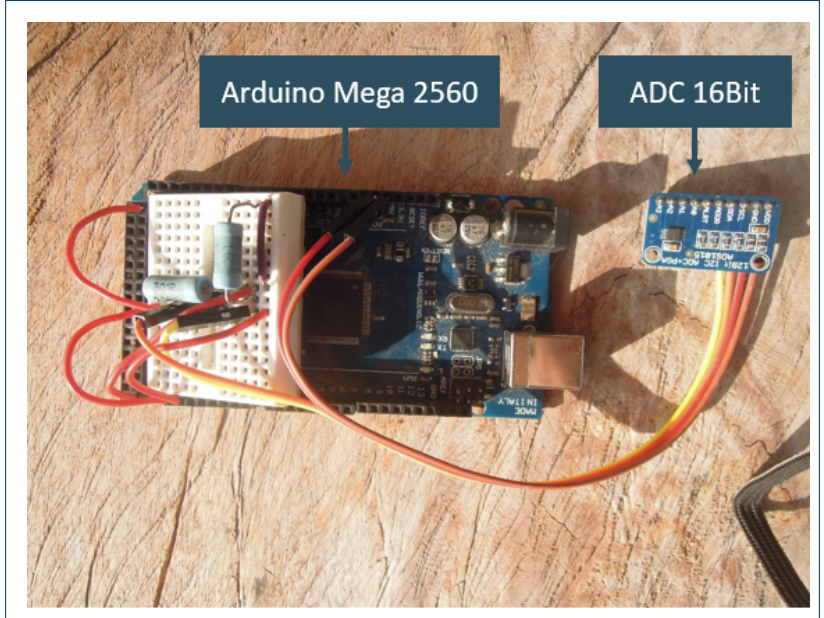

Gambar 3 Unit pengumpul.

Analog to Digital Converter yang dipakai di unit pengumpul berfungsi untuk menangkap sinyal analog dari geophone trigger. Sistem trigger yang dipakai pada alat ini menggunakan gangguan seismik yang terekam oleh geophone. Ketika gangguan seismik melebihi batas yang ditentukan maka akan dianggap sebagai waktu nol pada rekaman data seismik masing masing geophone. ADC yang digunakan memiliki resolusi yang lebih kecil yaitu 16 bit dan kecepatan sampling mencapai 860 sampel per detik.

Unit pengumpul dan unit digitasi saling terhubung dengan komunikasi berjenis I2C namun perangkat keras dari komunikasi ini hanya mampu menyalurkan data tidak lebih panjang dari dua meter. Oleh karena itu diperlukan penguat sinyal berupa i2c extender pada unit digitasi ini agar komunikasi dapat terjalin dengan kabel hingga 50 meter.

C.Software Pengoperasian Alat

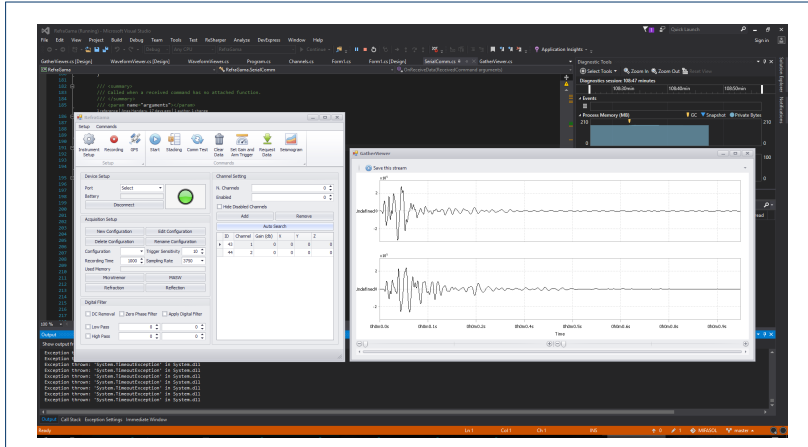

Gambar 4 Hasil uji coba lapangan.

Untuk mengoperasikan alat ini dibuatlah sebuah perangkat lunak (Software) yang dinamakan RefraGama. RefraGama menghubungkan perangkat komputer dengan Unit Pengumpul melalui komunikasi serial. Operator mengoperasikan alat melalui software RefraGama ini.

Pada perangkat lunak ini operator dapat mengatur kecepatan cuplik, durasi perekaman dari unit-unit digitasi. Operator juga dapat memasukan informasi geometri dari survey refraksi yang dilakukan dengan memasukan koordinat lokalnya. Kualitas data juga dapat ditingkatkan dengan pilihan opsi digital filter dari DC removal.

Uji coba lapangan dilakukan dengan menggunakan konfigurasi dengan spasi geophone 2 meter. Sumber gangguan seismik diletakan ssejauh 2 meter dari geophone yang terdekat. Gambar 4 menunjukkan hasil uji coba lapangan dan tampilan RefraGama pada saat pengukuran lapangan dilakukan.

\section{Kesimpulan}

1 Penelitian ini telah menjadi salah satu langkah membangun kemandirian dalam instrumentasi geofisika,

2 Telah terbangun purwarupa instrumen akuisisi data seismik refraksi yang murah dan reliabel namun masih perlu dilakukan packing yang baik,

3 Uji sinkronisasi unit digitasi menunjukkan tidak adanya jeda antarkanal,

4 Masih perlu dilakukan pengujian yang lainnya pada alat ini,

5 Perlu dibuat Petunjuk Pemakaian alat ini agar dapat digunakan dalam perkuliahan dan praktikum dengan instrumen yang dapat dibuat secara mandiri.

\section{Ucapan Terimakasih}

Penulis mengucapkan terimakasih kepada Fakultas MIPA UGM atas hibah penelitian yang telah diberikan.

\section{Penulis}

Wahyudi* dan Anas Setyo Handaru

Dari :

Jurusan Geofisika, Fakultas Matematika dan Ilmu Pengetahuan Alam, Universitas Gadjah Mada

Alamat :

Kode pos 55281, Yogyakarta, Indonesia

email : wahyudi_mipa@ugm.ac.id

Pustaka

1. Telford, W. M., Geldart, L. P. \& Sheriff, R. E., 1990. Applied Geophysics 2nd. New York: Cambridge University Press.

2. Sheriff, R. E. \& Geldart, L. P., 1995. Exploration Seismology. New York: Cambridge University Press. 